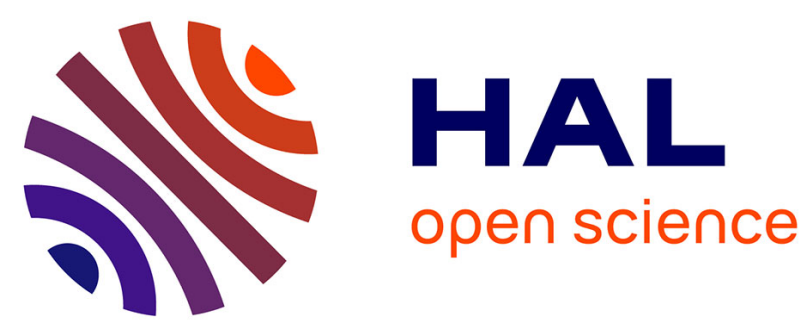

\title{
The State of Artificial Intelligence Research in the Context of National Security: Bibliometric Analysis and Research Agenda
}

\author{
Samuel Fosso Wamba, Ransome Epie Bawack, Kevin Carillo
}

\section{To cite this version:}

Samuel Fosso Wamba, Ransome Epie Bawack, Kevin Carillo. The State of Artificial Intelligence Research in the Context of National Security: Bibliometric Analysis and Research Agenda. 18th Conference on e-Business, e-Services and e-Society (I3E), Sep 2019, Trondheim, Norway. pp.255-266, 10.1007/978-3-030-29374-1_21. hal-02510128

\section{HAL Id: hal-02510128 \\ https://hal.inria.fr/hal-02510128}

Submitted on 17 Mar 2020

HAL is a multi-disciplinary open access archive for the deposit and dissemination of scientific research documents, whether they are published or not. The documents may come from teaching and research institutions in France or abroad, or from public or private research centers.
L'archive ouverte pluridisciplinaire HAL, est destinée au dépôt et à la diffusion de documents scientifiques de niveau recherche, publiés ou non, émanant des établissements d'enseignement et de recherche français ou étrangers, des laboratoires publics ou privés. 


\title{
The State of Artificial Intelligence Research in the Context of National Security: Bibliometric Analysis and Research Agenda
}

\author{
Samuel Fosso Wamba ${ }^{1}$, Ransome Epie Bawack ${ }^{1,2}$, and Kevin Daniel André Carillo ${ }^{1}$ \\ ${ }^{1}$ Toulouse Business School, 20 Boulevard Lascrosses, 31068 Toulouse, France \\ ${ }^{2}$ Toulouse 1 University Capitole, 2 Rue du Doyen-Gabriel-Marty, 31042 Toulouse, France \\ ransome.bawacketsm-education.fr
}

\begin{abstract}
Artificial intelligence (AI) is a growing research topic in national security due to the growing need for peaceful and inclusive societies, as well as for the maintenance of strong institutions of justice. As e-societies continue to evolve due to the advancements made in information and communication technologies (ICT), AI has proven crucial to guarantee the development of security measures, especially against growing cyberthreats and cyberattacks. This relevance has been translated into an explosive growth of AI applications for the improvement of decision support systems, expert systems, robotics, surveillance, and military operations that aim at ensuring national security. However, there is no bibliometric research on $\mathrm{AI}$ in national security, especially one that highlights current debates on the topic. This paper presents an overview of research on AI and national security, with emphasis on the research focus areas and debates central to research on the topic. We analyzed 94 references collected from the Web of Science (WoS) Core Collection and used VOS viewer software to analyze them. Based on these analyses, we identified 7 focus areas and 8 debates on AI in national security. We also identified the state and evolution of research on the topic in terms of main journals, authors, institutions, and countries. Our findings help researchers and practitioners better understand the state of the art of AI research on national security, and guides future research and development projects on the topic.
\end{abstract}

Keywords: National Security, Artificial Intelligence, Bibliometric Analysis, Military, Defense.

\section{Introduction}

Artificial intelligence (AI) is a growing research topic in national security (NS) due to the rising need for peaceful and inclusive societies, as well as for the maintenance of strong institutions of justice. National security refers to a State's ability to protect and defend its citizens by preserving the principles, standards, institutions and values of its society [1]. This implies conscious and purposeful actions taken to defend citizens from both military and non-military threats, both in the physical and digital world. To this 
end, nations are investing huge amounts in AI research to achieve military, information, and economic superiority, as well as technological leadership [2].

For over 40 years, military power has been the main instrument used to enforce NS [1]. This power is often demonstrated by the ability to develop and use technologies in security actions. This has been the case with nuclear technology, aerospace, biotechnology, internet and cyber technology. Today, research efforts on technology for NS are turned towards AI, which refers to computational techniques that give technology artefacts the ability to act like intelligent beings [3].

AI's significant potential for NS is mostly due to advancements in machine learning. It promises unique opportunities for autonomy, speed, scaling, predictability, and explicability, all of which are essential for actions towards NS. This far, it has revolutionized intelligence, surveillance, reconnaissance, logistics, cybersecurity, command and control, autonomous vehicles, and lethal autonomous weapon systems (LAWS) [4]. However, there are several debates central to the use and consequences of using AI to ensure NS.

Ethical dilemmas on the framework within which AI should be used to enforce NS $[5,6]$ as well as in modern warfare $[7,8]$ are some of the most serious issues on using AI for IS. Also, it is becoming impossible for a State to ensure NS without considering the impact and implications this could have on other States [9]. This is due to the symbiotic relationship between national and global security, the latter evolving from the effects of globalization. This blurs the lines of territoriality in today's society, making NS a global concern.

AI researchers on NS in both the private sector and academia have made significant technical progress in the last five years at unprecedented speeds [4]. However, very little is known about the extent of this research in academic literature and the current debates they focus on that could help solve some of the issues on the topic at hand. Thus, we present an overview of academic research on AI in NS, with emphasis on the debates central to research on the topic. To this end, we use bibliometrics, which is an established method used to analyze specific research areas and draw meaningful insights that could guide future research and practice $[10,11]$.

There are recent studies that use bibliometrics to understand academic literature on global AI research [12], AI in health [13], and on sustainable AI [14]. To the best of our knowledge, there is no research that seeks to analyze current literature on AI in the context of NS especially using bibliometrics. Therefore, one of the main contributions we make for researchers and practitioners is to provide an overview of the structure and development of academic literature on AI in NS. Secondly, we reveal the trends and themes that lead the discussions and research on the topic. Thirdly, we identify current research gaps that could guide future research plans and inform practitioners or policymakers on current debates that could influence related policies.

Our work reveals the complexities of debates related to AI in NS especially given the implications and relative importance for global security in the physical and digital world. Thus, it helps both research and NS institutions manage and evaluate their research projects by setting the appropriate research priorities and allocating resources to match the current needs of the topic. In section 2, we present our research methodology, followed by our results in section 3 , and then discussion and implications in section 4 . 


\section{Methodology}

This study is based on a bibliometric analysis of AI research in the context of NS. Bibliometrics focuses on obtaining quantitative facts on written documents such as output, impact, and collaboration [15]. This approach has proven to be effective for capturing the temporal content of research topics and to identify research trends [12] like what we seek to do in this study. It has been used in information systems (IS) research and is found to be a complete and efficient assessment method of academic literature [16]. It has also been used to analyze and interpret existing IS literature in several contexts $[17,8]$.

The steps we used in our bibliometric analysis were adapted from the six steps proposed by Cuellar et al., (2016). This adaptation led to the following four steps: (i) define the academic field and the context of the study, (ii) identify and collect literature on the topic, (iii) conduct bibliometric analysis, and (iv) present and comment the results. Step four (4) is the results and discussion section of this paper.

\subsection{Define the Academic Field and the Context of Study}

The academic field concerned in this study is that of AI, and the context is that of NS. IS being a field that studies the link between people, processes and technology in relation to organizations and society, IS research can make significant contributions to discussions on the use of AI-based IS for NS.

\subsection{Identify and Collect Literature on the Topic}

We collected bibliometric data from the Web of Science (WoS) database. This database is one of the most commonly used databases for bibliometric analysis due to its huge journal coverage and reliability of references $[19,20]$. Table 1 presents our search string and the results we obtained from the WoS core collection. The asterisk used next to the keywords enables the search query located and add any available literature with related keywords in the database. This search was conducted on May 6, 2019, at 9 pm. Thus, our analysis is based on the 100 publications obtained from the WoS search. We downloaded the complete bibliometric data in the WoS format for analysis.

Table 1. Web of Science search results

\begin{tabular}{|c|c|c|}
\hline Search String & Time Span & $\begin{array}{l}\text { Results (from Web } \\
\text { of Science Core } \\
\text { Collection) }\end{array}$ \\
\hline $\begin{array}{l}\text { 1. (TS=("Artificial Intelligence*" AND "National } \\
\text { Defense*")) AND LANGUAGE: (English) AND } \\
\text { DOCUMENT TYPES: (Article) }\end{array}$ & All years & 1 \\
\hline $\begin{array}{l}\text { 2. (TS=("Artificial Intelligence*" AND "National } \\
\text { Security*")) AND LANGUAGE: (English) AND } \\
\text { DOCUMENT TYPES: (Article) }\end{array}$ & All years & 4 \\
\hline
\end{tabular}




\begin{tabular}{|c|c|c|}
\hline 3. (TS=("Artificial Intelligence*" AND Military*)) & All years & 96 \\
\hline \multicolumn{3}{|l|}{ AND LANGUAGE: (English) AND DOCUMENT } \\
\hline \multicolumn{3}{|l|}{ TYPES: (Article) } \\
\hline 1 OR 2 OR 3 & All years & 100 \\
\hline
\end{tabular}

\subsection{Conduct Bibliometric Analysis}

To conduct bibliometric analysis, we used the software called VOSviewer version 1.6.10. This tool is recognized for its ability to conduct sophisticated bibliometric analyses and provide reliable results with great visualizations to facilitate understanding [21]. With this software, we were able to conduct co-authorship, co-occurrence, citation, bibliographic coupling, and co-citation analyses based on the data we collected.

In the next section, we present the results of the bibliometric analysis, with emphasis on authors, institutions, countries, publications, research themes and trends that make up current discussions and debates.

\section{$3 \quad$ Results}

The results of this study are presented and discussed in two sections that answer the following questions: (i) what is the status and evolution of academic research on AI in the context of NS; (ii) what is the current research focus and trend driving debates on the topic?

\subsection{What is the Status and Evolution of Academic Research on AI in the Context of National Security?}

The first papers in the WoS database related to AI in the context of NS were published in 1991. These papers discussed the applications of AI in expert systems (ES) [22] and decision support systems (DSS) [23]. Since then, one could barely find up to five academic research articles published on the topic each year until 2017 when 14 publications were recorded. About 51 of the 100 articles found were published between 2013 and May 2019. This shows the rising interest by academic researchers in this topic that has barely been researched for the past 30 years. Moreover, using the keywords "national security" and "national defense", we obtained only four results whereas we obtained 96 results when we searched the WoS database using the term "military" with AI. This confirms that indeed, the military applications of AI have been the main focus of academic researchers as concerns NS. 35 out of the 100 articles were published in the area of engineering, 31 in computer science, 18 in operations research management science, 13 in business economics, 11 in international relations, 7 in social issues, 6 in government law, and 5 in robotics, 4 in telecommunications, 3 in instruments instrumentation, 2 in material science, and 2 in oceanography.

At this point when the academic research on AI in NS is still at a nascent stage, it is important to identify the most influential authors, publications, and collaborations in this research area. This could help researchers and practitioners decide with whom to 
collaborate on such projects, and to identify key players with whom to develop strategic partnerships related to this issue. To respond to this question, we performed co-authorship, citation, and co-citation analyses on the bibliometric data. The co-authorship analysis was done by institution, and country. The citation analysis was done by document, source, author, organization, and country. The co-citation analysis was done by cited references, cited sources, and cited authors.

Co-Authoring Research Institutions and Countries. This bibliometric analysis helps to interpret the structure of research collaboration networks on AI in NS. Hence, highlights the most influential countries and research institutions as well as the structure of research teams. Starting with the analysis of research institutions, the dispersion of literature on the topic is led by the United States Naval Institute - USN ( 3 documents, 83 citations) and the University of Oxford ( 3 documents, 6 citations). Only 13 out of 134 institutions have published at least two articles on AI in the context of NS.

There are three clusters of at least two institutions collaborating in this research area: cluster 1 consists of USN, Florida International University ( 2 documents, 92 citations), and the United States Army (2 documents, 12 citations). Cluster 2 consists of RAND Corporation ( 2 documents, 2 citations) and Stanford University ( 2 documents, 1 citation). Cluster 3 consists of the Chinese Academy of Science - CAS ( 2 documents, 9 citations) and the University of Chinese Academy of Science - UCAS (2 documents, 9 citations). Clusters 1 and 2 consists of US-based institutions while cluster 3 consists of Chinese institutions.

14 out of 32 countries identified in our analysis have published at least two papers on AI in NS. The three countries leading this research area are: USA (42 documents, 547 citations), England (12 documents, 47 citations), and China (10 documents, 137 citations). While China stands alone, England, Russia (2 documents, 1 citation) and the USA form an important research cluster, France (3 documents, 78 citations) and Singapore (3 documents, 1 citation) form another.

Publication, Journal, Reference and Author Citation and Co-Citation Analysis. To identify the most influential publications, journals and references in this research area, we used citation and co-citation analysis to rank them by popularity.

We assume that the most cited publications and journals are the most influential ones. Table 2 presents the 10 most influential publications and their characteristics. 71 journals were found to have published research on AI in NS. Those that have published at least two papers include expert systems with applications ( 8 documents, 183 citations), Bulletin of the atomic scientists ( 6 documents, 1 citation), European journal of operational research (5 documents, 56 citations), IET Radar, Sonar \& Navigation (3 documents, 9 citations), industrial robot an international journal ( 3 documents, 14 citations), interfaces ( 3 documents, 9 citations), and artificial intelligence ( 2 documents, 13 citations). The most cited references include are presented in Table 3 . We were also able to identify the most cited authors in this research area and their research interests as presented in Table 4 . 
Table 2. Most cited papers in research on AI in national security

\begin{tabular}{|c|c|c|c|c|}
\hline Article Title & Authors & Year & $\begin{array}{l}\text { \# of } \\
\text { Cita- } \\
\text { tions }\end{array}$ & Journal \\
\hline $\begin{array}{l}\text { The Use of Kalman Filter and Neural } \\
\text { Network Methodologies in Gas Tur- } \\
\text { bine Performance Diagnostics: A } \\
\text { Comparative Study }\end{array}$ & $\begin{array}{l}\text { Volponi, Allan } \\
\text { J., et al. }\end{array}$ & 2000 & 113 & $\begin{array}{l}\text { ASME Turbo Expo } \\
\text { 2000: Power for } \\
\text { Land, Sea, and Air. }\end{array}$ \\
\hline $\begin{array}{l}\text { Virtual Reality Surgery: Neurosur- } \\
\text { gery and the Contemporary Land- } \\
\text { scape }\end{array}$ & $\begin{array}{l}\text { Spicer, M. A., } \\
\text { \& Apuzzo, M. } \\
\text { L. }\end{array}$ & 2003 & 87 & Neurosurgery \\
\hline $\begin{array}{l}\text { Prognosis of bearing failures using } \\
\text { hidden Markov models and the adap- } \\
\text { tive neuro-fuzzy inference system. }\end{array}$ & $\begin{array}{l}\text { Soualhi, Ab- } \\
\text { denour, et al. }\end{array}$ & 2014 & 67 & $\begin{array}{l}\text { IEEE Transactions } \\
\text { on Industrial Elec- } \\
\text { tronics }\end{array}$ \\
\hline Intelligent lessons learned systems & $\begin{array}{l}\text { Weber, R., } \\
\text { Aha, D. W., \& } \\
\text { Becerra-Fer- } \\
\text { nandez, I. }\end{array}$ & 2001 & 66 & $\begin{array}{l}\text { Expert systems with } \\
\text { applications }\end{array}$ \\
\hline $\begin{array}{l}\text { Problem solving and knowledge in- } \\
\text { ertia }\end{array}$ & Shu-hsien Liao & 2002 & 41 & $\begin{array}{l}\text { Expert systems with } \\
\text { applications }\end{array}$ \\
\hline $\begin{array}{l}\text { Probabilistic roadmap-based path } \\
\text { planning for an autonomous un- } \\
\text { manned helicopter. }\end{array}$ & $\begin{array}{l}\text { Pettersson, P. } \\
\text { O., \& Doherty, } \\
\text { P. }\end{array}$ & 2006 & 37 & $\begin{array}{l}\text { Journal of Intelligent } \\
\text { \& Fuzzy Systems }\end{array}$ \\
\hline $\begin{array}{l}\text { Artificial intelligence technologies } \\
\text { for robot assisted urban search and } \\
\text { rescue. }\end{array}$ & John G.Blitch & 1996 & 35 & $\begin{array}{l}\text { Expert systems with } \\
\text { applications }\end{array}$ \\
\hline $\begin{array}{l}\text { Case-based decision support system: } \\
\text { Architecture for simulating military } \\
\text { command and control }\end{array}$ & Shu-hsien Liao & 2000 & 34 & $\begin{array}{l}\text { European Journal of } \\
\text { Operational Re- } \\
\text { search }\end{array}$ \\
\hline $\begin{array}{l}\text { Human-Robot Interaction: Status } \\
\text { and Challenges }\end{array}$ & $\begin{array}{l}\text { Thomas B. } \\
\text { Sheridan }\end{array}$ & 2016 & 32 & Human factors \\
\hline $\begin{array}{l}\text { Virtual reality and telepresence for } \\
\text { military medicine }\end{array}$ & $\begin{array}{l}\text { Richard M. Sa- } \\
\text { tava }\end{array}$ & 1995 & 31 & $\begin{array}{l}\text { Computers in biol- } \\
\text { ogy and medicine }\end{array}$ \\
\hline
\end{tabular}

Table 3. Most cited references by researchers on AI in national security

\begin{tabular}{lllll}
\hline Article & Authors & Year & $\begin{array}{l}\text { \# of Ci- } \\
\text { tations }\end{array}$ & $\begin{array}{l}\text { Type of Pub- } \\
\text { lication }\end{array}$ \\
\hline $\begin{array}{l}\text { Superintelligence: Paths, dangers, } \\
\text { strategies. Oxford: Oxford Univer- } \\
\text { sity Press. }\end{array}$ & Bostrom, N. & 2014 & 4 & Book \\
$\begin{array}{l}\text { Governing lethal behavior in auton- } \\
\text { omous robots. }\end{array}$ & Arkin, Ronald. & 2009 & 3 & Book
\end{tabular}




$\begin{array}{lllll}\begin{array}{l}\text { Swarming and the Future of Con- } \\ \text { flict }\end{array} & \begin{array}{l}\text { Arquilla, John, and } \\ \text { David Ronfeldt }\end{array} & 2000 & 3 & \text { Book } \\ \begin{array}{l}\text { Artificial intelligence: A modern } \\ \text { approach }\end{array} & \begin{array}{l}\text { Russell, Stuart, and } \\ \text { Peter Norvig }\end{array} & 1995 & 3 & \text { Book } \\ \begin{array}{l}\text { Weapons, Autonomous. An open } \\ \text { letter from AI \& robotics research- } \\ \text { ers. }\end{array} & \begin{array}{l}\text { Signed by 20 (Hawk- } \\ \text { ing, Musk, Woz- } \\ \text { niak...) }\end{array} & & 3 & \text { Open Letter } \\ \begin{array}{l}\text { Proceedings of IEEE interna- } \\ \text { tional conference on neural net- } \\ \text { Korks }\end{array} & \begin{array}{l}\text { Kennedy, James, } \\ \text { and R. C. Eberhart }\end{array} & 1995 & \text { Conference } \\ \end{array}$

Table 4. Most cited authors by researchers on AI in national security

\begin{tabular}{lll}
\hline Author & \# of Citations & Research field \\
\hline Vukobratovic M. & 24 & Robotics \\
Bostrom N. & 9 & Superintelligence \\
Good I.J. & 9 & Bayesian Methods \\
McCulloch W.S. & 9 & Mathematical Biophysics \\
Kim J. & 8 & Theoretical AI \\
Laird J.E. & 6 & Cognitive Architecture \\
Freedberg Jr Sydney J. & 6 & Art Historian \\
Moffat J & 6 & Genetic Interactions \\
\hline
\end{tabular}

\subsection{What is the Current Research Focus and Debates on AI in National Security?}

The results in this section are based on bibliographic coupling and co-occurrence mappings. Bibliographic coupling was analyzed by document, source, author, organization, and country. Co-occurrence analysis was done by keywords (all, author-provided, and Keywords plus) and content analysis of the terms in the title and abstracts.

Research Focus of AI in the Context of National Security. To identify the main research topics on AI in the context of NS, we conducted keyword analysis through cooccurrences by concentrating on keywords provided by authors. This technique counts the number of co-occurrences of keywords and the greater the frequency, the greater the relevance of the topic. VOS viewer identified 359 keywords. Figure 1 illustrates the main keywords, the colors representing the clusters, the sizes representing the frequency, and the lines representing the links between keywords. The smaller the distance between the nodes, the stronger the relationship between them (how many times they occur together in the same paper). Figure 1 is based on a threshold of 2 occurrences, representing 25 keyword co-occurrences. The most common keywords leading the main clusters are: artificial intelligence (36 occurrences, lemon green), robotics (5 
occurrences, red), autonomy ( 3 occurrences, purple), intelligent agents ( 3 occurrences, orange), drones ( 2 occurrences, sky blue), decision support systems (4 occurrences, blue), neural nets ( 2 occurrences, green).

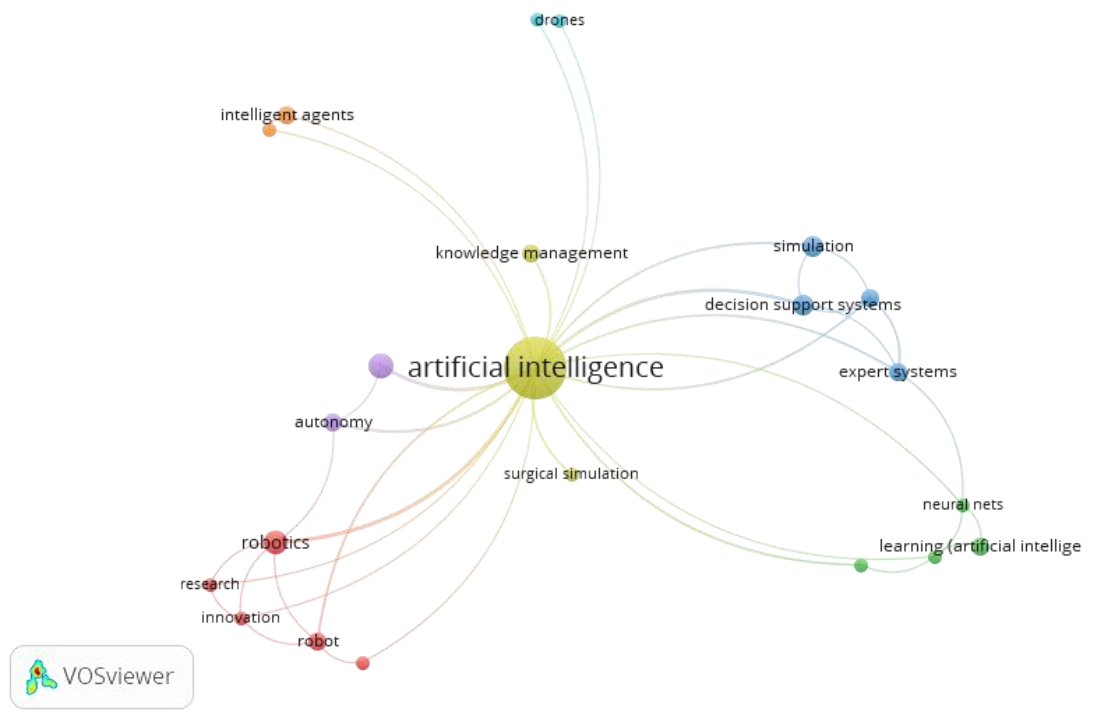

Fig. 1. Co-occurrence network of author keywords in publications. Related to AI in national security

These clusters represent seven research focus area on AI in NS. Cluster 1 represents general AI research in the context of NS. Items in this cluster include artificial intelligence, decision support systems, economics, expert systems, future, military, models, simulation, and surgical simulation. Cluster 2 represents research that focuses on the learning capabilities of AI. The items in this cluster include classification, feature extraction, identification, learning (artificial intelligence), networks, neural nets, pattern recognition, performance, recognition. Cluster 3 represents research that focuses on the use of AI for decision support. Items in this cluster include decision support systems, decision-making, information, intelligence, intelligent agents, knowledge management, management. Cluster 4 represents the category of research that focuses on AI algorithms. Items in this cluster include algorithm, genetic algorithm, neural network, neural-networks, particle swarm optimization, and PID controller.

Cluster 5 represents research that focuses on the research and development of intelligent systems. The items in this cluster include innovation, intelligent control, research, robot, robotics, systems. Cluster 6 represents research that focuses on the applications of AI algorithms, systems or technologies in NS. Items in this cluster include algorithms, drones, robots, security, and state. Cluster 7 represents research on the use of machine learning for system autonomy. Items in this cluster include autonomy and machine learning. 
Debates on AI in National Security. We identified current trends using KeyWords Plus analysis. KeyWords Plus is the result of Thomson Reuters editorial expertise in Science. The editors review the titles of all references and highlight additional relevant but overlooked keywords that were not listed by the author or publisher. This technique helps to uncover more papers that may not have appeared in the search due to changes in scientific keywords over time, showing the evolution of the field. 14 out of the 147 keyWords occur at least twice. The most recurrent are neural networks (3), algorithms (3) and systems (3).

KeyWords plus formed three clusters. Cluster 1 ( 3 items) includes Classification, Networks, Recognition. Cluster 2 ( 2 items) includes Algorithm and Identification. Cluster 3 (2 items) includes Future and Neural-networks. This depicts the growing interest in using neural network algorithms for identification, pattern recognition and classification of data for AI systems of the future.

Through the bibliographic coupling of documents, we were able to classify current AI research in the context of NS into eight research themes as presented in Table 2. The table shows how debates on AI have evolved since 1991 when the focus was on the applications of neural networks, till now that research focuses more on AI ethics, principles, and governance. We also notice that since 2017, world peace and conflict resolution became a major research theme thereby affirming the need for more research in this nascent theme.

Table 5. Research themes for AI in the context of national security.

\begin{tabular}{|c|c|c|}
\hline $\begin{array}{l}\text { Research } \\
\text { Theme }\end{array}$ & $\begin{array}{l}\text { Start } \\
\text { date }\end{array}$ & Description \\
\hline $\begin{array}{l}\text { AI Ethics, } \\
\text { Principles, } \\
\text { and Govern- } \\
\text { ance }\end{array}$ & 2018 & $\begin{array}{l}\text { Focuses on the ethics and control/laws governing the use of ma- } \\
\text { chines/robots/automated systems by governments for military or sur- } \\
\text { veillance actions. }\end{array}$ \\
\hline $\begin{array}{l}\text { World Peace } \\
\text { and Conflict } \\
\text { Resolution }\end{array}$ & 2017 & $\begin{array}{l}\text { Focuses on the challenges the military faces as technology and AI con- } \\
\text { tinues to spread. It emphasizes the fact that world peace is threatened } \\
\text { by the democratization of technology. As a result, nations are losing } \\
\text { their military control over the population. This research cluster investi- } \\
\text { gates how nations can try to manage this situation. }\end{array}$ \\
\hline $\begin{array}{l}\text { Robotics in } \\
\text { Modern } \\
\text { Warfare }\end{array}$ & 2017 & $\begin{array}{l}\text { Focuses on how robotics is changing modern warfare, with emphasis } \\
\text { on the legal and geopolitical implications. Advances are made on how } \\
\text { autonomous systems and weapons like drones are using advanced } \\
\text { combat techniques like swarming and hiving. }\end{array}$ \\
\hline $\begin{array}{l}\text { Future \& } \\
\text { Post-Hu- } \\
\text { manity }\end{array}$ & 2017 & $\begin{array}{l}\text { Focuses on research related to the design of algorithms the and manu- } \\
\text { facturing of technologies for the future (post-humanity). }\end{array}$ \\
\hline $\begin{array}{l}\text { Human Per- } \\
\text { formance } \\
\text { Enhance- } \\
\text { ment }\end{array}$ & 2015 & $\begin{array}{l}\text { Focuses on using AI to enhance human performance and national de- } \\
\text { fense strategies. }\end{array}$ \\
\hline
\end{tabular}




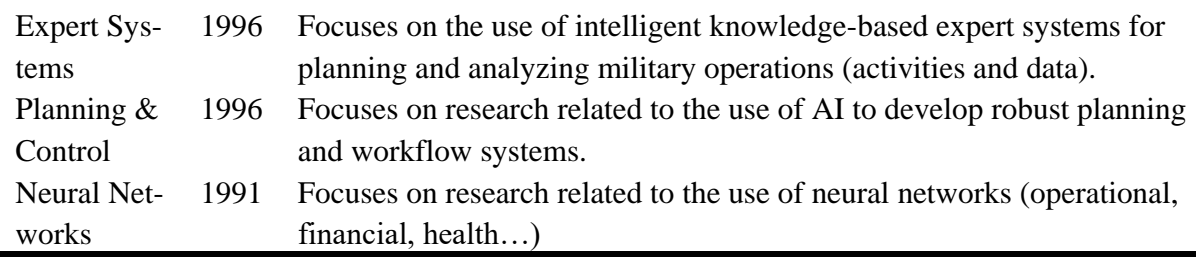

\section{Discussion and Research Agenda}

In this paper, we have investigated the state of AI research in the context of NS. We used bibliometric analyses to identify the key players in this research area, as well as their research focus and debates on AI research in NS. Due to the limited amount of academic research published in this area, we found this method most suitable to help identify key connections and relationships in the field in terms of authors, journals, research themes, research institutions, and even countries. Our results provide an overview of the research domain and provide information that could help researchers and practitioners plan their limited resources and develop strategic partnerships with the key players identified. It also informs on the key debates that influence decisions regarding using AI to ensure NS both in the digital and physical worlds. Therefore, from our results, we can arrive at the following conclusions.

$\mathrm{AI}$ in the context of NS is a very complex research area. This interdisciplinary research area involving over 12 major disciplines need is proof of this complexity This calls for the need to collect and integrate research on the topic in other to have a holistic view and to draw relevant conclusions for the conceptualization of AI for NS. Although this is a relatively young and growing research area, it is timidly rising as people get more aware of the dangers of AI and the rising NS issues worldwide. The fact that research on AI in NS started with applications in ES and DSS shows that the field of IS has a major role to play in this research area. Therefore, IS researchers need to get fully involved in this research field and contribute to how AI-enabled IS can contribute to ensuring NS.

As concerns the state and evolution of this research area, the facts reveal that there is still much to be done on this topic as it has not received the attention it deserves. The most cited papers in the 1990s focus on the use of AI in urban search and rescue, and in medicine. in this area of research was a publication in the year 2000 on neural networks. However, in recent years, the most cited paper was published in 2016 on the status and challenges of human-robot interactions. This shows the evolution of this research area from an application phase to an interaction phase. This explains the increasing number of debates on AI ethics and principles. Only 13 institutions, 14 countries and 71 journals have published academic research on AI in the context of NS. This is certainly not enough given how many disciplines can contribute to discussions on the topic. Thus, there is a need for more quality academic publications on the topic in wellrecognized journals so that they can be more accessible to a wider audience. The most referenced publication is on the paths, dangers, and strategies of superintelligence. This is proof of the concerns people have on the use of AI technologies. The relevance of 
research on AI in NS was recognized by the United Nations in the sustainable development goals 2030 agenda where it features as part of goal 16 [24]. As 2030 approaches, academic researchers need to increase their efforts towards making meaningful contributions to the attainment of this goal.

As concerns current research focus and debates on AI in NS, we identified 7 major focus areas and 8 debates. The 7 focus areas are robotics, planning, governance, war, military, conflict resolution, community, internet, power, and organization. These focus areas cover both the physical and the digital world, showing that although much still needs to be done, researchers have identified these areas as key important to this research area. Table 5 describes the 8 debates in this research area from 1991 until now. All this information is especially important for State institutions when considering the use of AI in NS policies. They are also relevant to researchers seeking to use this information to provide answers or solutions to existing debates or open new ones. The literature also indicates the need for future research about the non-military-oriented use of AI for NS. For example, using technologies like blockchain, it could be interesting to investigate how people can connect with each other securely to ensure mutual protection before intervention from armed forces.

This paper has some limitations, particularly associated with bibliometrics. Firstly, some research papers might have been omitted as a result of the keywords used. To mitigate this risk, we used asterisks to increase the search sphere to related keywords. Secondly, our results are based on results from the WoS Core Collection database. Our work could be extended or complemented by analyzing other databases like Scopus or Google Scholar. Authors can also decide to evaluate published through other means or outlets such as conference proceedings, practice-oriented magazines, or doctoral theses. Perhaps there is more accessible research in these outlets, possibly published in other languages as well.

\section{References}

[1] O. Segun, "National Security versus Global Security," UN Chronicle: The Magazine of the United Nations, 2014. [Online]. Available: https://unchronicle.un.org/article/national-security-versus-global-security.

[2] G. Allen and T. Chan, Artificial intelligence and national security. Belfer Center for Science and International Affairs Cambridge, MA, 2017.

[3] A. AKGÜL, “Artificial Intelligence Military Applications," Ankara Üniversitesi SBF Derg., vol. 45, no. 1, 2015.

[4] D. S. Hoadley and N. J. Lucas, Artificial Intelligence and National Security. Congressional Research Service, 2018.

[5] C. Cath, S. Wachter, B. Mittelstadt, M. Taddeo, and L. Floridi, "Artificial intelligence and the 'good society': the US, EU, and UK approach," Sci. Eng. Ethics, vol. 24, no. 2, pp. 505-528, 2018.

[6] Y.-L. Teo, "Regulating Artificial Intelligence: An Ethical Approach,” 2018.

[7] D. Garcia, "Lethal Artificial Intelligence and Change: The Future of International Peace and Security," Int. Stud. Rev., vol. 20, no. 2, pp. 334-341, 2018. 
[8] J. Johnson, "Artificial intelligence \& future warfare: implications for international security," Def. Secur. Anal., pp. 1-23, 2019.

[9] Z. D. Clopton, "Territoriality, Technology, and National Security," U. Chi. L. Rev., vol. 83, p. 45, 2016.

[10] D. Hicks, P. Wouters, L. Waltman, S. De Rijcke, and I. Rafols, "Bibliometrics: the Leiden Manifesto for research metrics," Nat. News, vol. 520, no. 7548, p. 429, 2015.

[11] J. King, "A review of bibliometric and other science indicators and their role in research evaluation,” J. Inf. Sci., vol. 13, no. 5, pp. 261-276, 1987.

[12] J. Niu, W. Tang, F. Xu, X. Zhou, and Y. Song, "Global research on artificial intelligence from 1990-2014: Spatially-explicit bibliometric analysis," ISPRS Int. J. GeoInformation, vol. 5, no. 5, p. 66, 2016.

[13] B. X. Tran et al., "Global Evolution of Research in Artificial Intelligence in Health and Medicine: A Bibliometric Study,” J. Clin. Med., vol. 8, no. 3, p. 360, 2019.

[14] S. Larsson, M. Anneroth, A. Felländer, L. Felländer-Tsai, F. Heintz, and R. Cedering Ångström, "Sustainable AI: An inventory of the state of knowledge of ethical, social, and legal challenges related to artificial intelligence," 2019.

[15] S. Corrall, M. A. Kennan, and W. Afzal, "Bibliometrics and research data management services: Emerging trends in library support for research," Libr. Trends, vol. 61, no. 3, pp. 636-674, 2013.

[16] A. Stewart and J. L. Cotton, "Does 'Evaluating Journal Quality and the Association for Information Systems Senior Scholars Journal Basket...' Support the Basket with Bibliometric Measures?," AIS Trans. Replication Res., vol. 4, no. 1, p. 12, 2018.

[17] A. Renaud, I. Walsh, and M. Kalika, "Is SAM still alive? A bibliometric and interpretive mapping of the strategic alignment research field," J. Strateg. Inf. Syst., vol. 25, no. 2, pp. 75-103, 2016.

[18] M. J. Cuellar, H. Takeda, R. T. Vidgen, and D. Truex, "Ideational Influence, Connectedness, and Venue Representation: Making an Assessment of Scholarly Capital.," J. AIS, vol. 17, no. 1, p. 3, 2016.

[19] P. Mongeon and A. Paul-Hus, "The journal coverage of Web of Science and Scopus: a comparative analysis," Scientometrics, vol. 106, no. 1, pp. 213-228, 2016.

[20] F. Garrigos-Simon, Y. Narangajavana-Kaosiri, and I. Lengua-Lengua, "Tourism and sustainability: A bibliometric and visualization analysis," Sustainability, vol. 10, no. 6, p. 1976, 2018.

[21] N. J. Van Eck and L. Waltman, "VOSviewer-Visualizing scientific landscapes..[S1: sn]," Acesso em, vol. 12, 2017.

[22] G. Woolsey, "On Inexpert Systems and Natural Intelligence in Military Operations Research,” Interfaces (Providence)., vol. 21, no. 4, pp. 2-10, 1991.

[23] F. C. C. Dargam, E. P. L. Passos, and F. D. R. Pantoja, "Decision support systems for military applications,” Eur. J. Oper. Res., vol. 55, no. 3, pp. 403-408, 1991.

[24] S. D. Keesstra et al., "The significance of soils and soil science towards realization of the United Nations Sustainable Development Goals," Soil, 2016. 